\title{
Influence Factors and Correction coefficient for Energy Consumption of Electric Vehicles
}

\author{
Xiao $\mathrm{Li}^{1,2^{*}}$, Runze $\mathrm{Gao}^{1}$, and Haitao $\mathrm{Yu}^{1}$ \\ ${ }^{1}$ Research Institute of Highway Ministry of Transport, Beijing 100088, China \\ ${ }^{2}$ School of Mechanical Engineering, Beijing Institute of Technology, Beijing 100081, China
}

\begin{abstract}
With the application of electric vehicles, the problem of energy consumption has been widely concerned. Fixed operating conditions energy consumption in the laboratory environment was used for vehicle identification, which made big difference from the actual situation. The paper was based on the actual operation data of the vehicles. The influence factors of energy consumption have been put forward through theoretical analysis. The correction factor was calculated by big data analysis and statistical fitting. The actual energy consumption of electric vehicles can be more accurately estimated through the research results.
\end{abstract}

\section{Introduction}

Electric vehicles are strategic emerging industry in automobile industry of China. The application of electric vehicles plays a positive role in improving the energy consumption structure, reducing air pollution, and promoting the transformation and upgrading of the transportation industry.

Driving range is directly determined by the energy consumption of electric vehicles. How to estimate the energy consumption of electric vehicles more accurately has become a widespread concern of scholars at home and abroad. At present, researches on energy consumption of pure electric vehicles are mostly fixed working conditions in the laboratory environment. For example, the NEDC (New European Driving Cycle) cycle is currently adopted in China and Europe ${ }^{[1]}$, and the WLTC (Worldwide Harmonized Light Vehicles Test Cycle) cycle currently being prepared for application ${ }^{[2]}$. However, in the actual use process, there is a big gap between the energy consumption of pure electric vehicles and the laboratory environment. In order to analyze the actual operation process on the vehicle energy consumption rate, Yi et al. analyzed the sensitivity of driving style to vehicles ${ }^{[3]}$. $\mathrm{Li}$ et al. studied the classification and recognition methods of drivers' driving styles further ${ }^{[4]}$. Liu et al. analyzed the influence of ambient temperature on energy consumption of electric vehicles ${ }^{[5]}$. Nonetheless, all the above analyses are quantitative and fail to accurately explain the influence of various factors on energy consumption.

In conclusion, current researches on energy consumption of pure electric vehicles are mostly based on fixed working conditions and drivers' driving styles. Other influencing factors in actual operation have received less attention. It is difficult to estimate the energy consumption of electric vehicles in the practical application process, which is not conducive to saving energy and reducing consumption of vehicles, but also affects the estimation and judgment of the actual driving range to a certain extent, resulting in the "range anxiety" problem in the application of electric vehicles.

Therefore, the influencing factors of the energy consumption of electric vehicles in the actual operation are analyzed in the paper, and the correction coefficient of each influencing factor is calculated through the collection, statistics and fitting of the operation big data.

\section{Theoretical Analyses}

At every moment when a pure electric vehicle travels, the power emitted by the motor is always equal to the sum of the power consumed by the mechanical transmission loss and various forms of resistance. The main resistance encountered by the car in the process of running is rolling resistance, slope resistance, air resistance and acceleration resistance. Corresponds to the resistance of the car, the resistance power consumed by automobile running includes rolling resistance power, slope resistance power, air resistance power and acceleration resistance power.

(1) The formula for calculating the rolling resistance power consumed to overcome the rolling resistance is as follows:

$$
P_{f}=\frac{G f \cos \alpha}{3600} v
$$

Where $G$ is the total gravity of the car; $f$ is the rolling resistance coefficient; $\alpha$ is the road slope; $v$ is the speed.

\footnotetext{
*Corresponding author: x.li@rioh.cn
} 
(2) The formula of slope resistance power consumed to overcome slope resistance is as follows:

$$
P_{i}=\frac{G f \sin \alpha}{3600} v
$$

(3) The formula of the air resistance power consumed to overcome the air resistance is as follows:

$$
P_{w}=\frac{C_{D} A v^{3}}{3600 \times 21.15} v=\frac{C_{D} A v^{3}}{76140}
$$

Where $C_{D}$ is air resistance coefficient; $A$ is the windward area of the vehicles.

(4) The formula of acceleration power consumed to overcome acceleration resistance is as follows:

$$
P_{j}=\frac{\delta G v}{3600 g} j
$$

Where $\delta$ is rotation mass conversion; $\mathrm{j}$ is the acceleration.

Based on the above, the driving power of electric vehicles can be expressed as follows:

$P_{e} \eta_{T}=P_{f}+P_{w}+P_{i}+P_{j}$

Further, the power balance equation of electric vehicles is shown as follows:

$P_{e}=\frac{1}{\eta_{T}}\left(\frac{G f v \cos \alpha}{3600}+\frac{G v \sin \alpha}{3600}+\frac{C_{D} A v^{3}}{76140}+\frac{\delta G v j}{3600 g}\right)$ (6)

Formula 6 shows the factors influencing energy consumption of the same vehicle in actual operation. Vehicle energy consumption is affected by factors such as running speed and ambient temperature at running time, after removing driver influence factors.

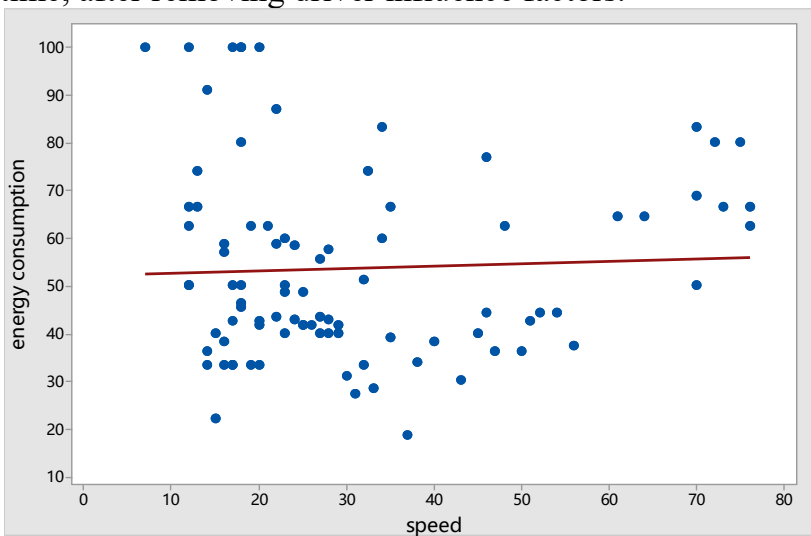

Fig. 1. The distribution of speed and energy consumption data

In order to ensure that the speed interval division method is clear when calculating the correction factor, the speed distribution of electric vehicles was further analyzed. The proportion of each speed interval was shown in Figure 2.

As can be seen from Figure 2, the maximum average speed of electric trucks is between $15 \mathrm{~km} / \mathrm{h} \sim 30 \mathrm{~km} / \mathrm{h}$. More than 50 accounted for a relatively small number. Top speed no more than 75 , generally. The reason is that electric trucks are mainly engaged in urban logistics and distribution, Subject to the city speed limit and road limit, High speed operating conditions are less than that of fuel cars.

Based on the above analysis, the velocity interval is divided into five, respectively $\mathrm{v} \leq 20,20<\mathrm{v} \leq 30, \quad 30<$ $\mathrm{v} \leq 40,40<\mathrm{v} \leq 50, \mathrm{v}>50$. The interval partition was

\section{Correction Factor of Speed}

The number of cars in China has reached 260 million. Meanwhile, the intensity of car travel has also been gradually improved in China. Urban traffic jams are becoming more frequent, especially during the morning and evening rush hours. When the road is congested, the vehicle is running at low speed and repeatedly accelerating and decelerating which was called the low efficiency operating interval. Energy consumption is significantly affected in this interval. The impact of operating speed on energy consumption is analyzed as follows.

The driving speed and corresponding energy consumption data of the electric truck are collected through the vehicle operation monitoring platform. The sample size was more than 100 vehicles. The distribution of speed and energy consumption data was shown in Figure 1.

As can be seen from Figure 1, the running speed range of the electric truck is about $0 \mathrm{~km} / \mathrm{h} \sim 75 \mathrm{~km} / \mathrm{h}$. The operating energy consumption range is about 20 $\mathrm{kWh} / 100 \mathrm{~km} \sim 100 \mathrm{kWh} / 100 \mathrm{~km}$. The average running speed of electric cars is lower than that of conventional fuel cars. The distribution of energy consumption is also different from that of conventional fuel vehicles. Low energy consumption area basically appears in the range of $20 \mathrm{~km} / \mathrm{h} \sim 50 \mathrm{~km} / \mathrm{h}$.

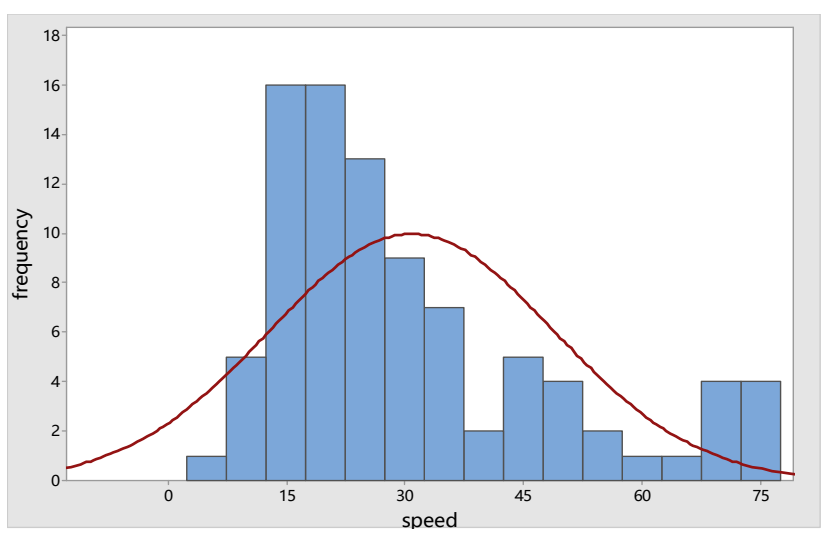

Fig. 2. The proportion of each speed interval used to calculate the operating speed correction for energy consumption.

By using regression analysis and curve fitting in the Minitab software, the cumulative probability density of the energy consumption for electric vehicle models in each speed range can be calculated. The velocity of $v \leq 20$ was used as an example. The cumulative probability density distribution function and the average energy consumption value at $50 \%$ are shown in Figure 3.

As can be seen from Figure 3, the fitting curve of the function to the energy consumption is in good agreement. Vehicle energy consumption at $50 \%$ is $56.8 \mathrm{kWh} / 100 \mathrm{~km}$. Energy consumption at the $50 \%$ cumulative probability density at the speed of each interval was successively calculated as shown in the Figure 4. 


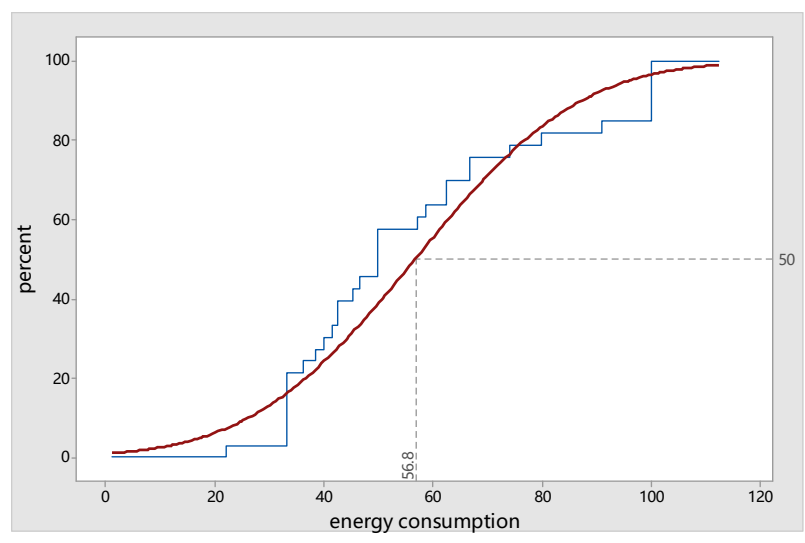

Fig. 3. The cumulative probability density distribution

As can be seen from Fig. 4, the average energy consumption of each speed interval was calculated. Further, the interval of $30<v \leq 40$ with the lowest energy consumption was taken as the benchmark, and the correction coefficient of energy consumption in each speed interval could be calculated, as shown in Table 1.

Table 1. Table of speed correction coefficient

\begin{tabular}{|c|c|c|}
\hline Speed range & $\begin{array}{c}\text { Energy } \\
\text { consumption }\end{array}$ & $\begin{array}{c}\text { correction } \\
\text { coefficient }\end{array}$ \\
\hline $\mathrm{v} \leq 20$ & $56.8 \mathrm{kWh} / 100 \mathrm{~km}$ & 1.23 \\
\hline $20<\mathrm{v} \leq 30$ & $48.6 \mathrm{kWh} / 100 \mathrm{~km}$ & 1.05 \\
\hline $30<\mathrm{v} \leq 40$ & $46.2 \mathrm{kWh} / 100 \mathrm{~km}$ & 1.00 \\
\hline $40<\mathrm{v} \leq 50$ & $46.7 \mathrm{kWh} / 100 \mathrm{~km}$ & 1.01 \\
\hline $\mathrm{v}>50$ & $61.2 \mathrm{kWh} / 100 \mathrm{~km}$ & 1.32 \\
\hline
\end{tabular}

\section{Correction Factor of Temperature}

The energy consumption of electric vehicles is greatly influenced by the temperature, which is determined by the chemical characteristics of the power battery of electric vehicles. The same research method as the operating speed correction factor was adopted. The impact of operating ambient temperature on energy consumption is analyzed as follows.

The operating ambient temperature and corresponding energy consumption data of the electric truck are collected through the vehicles operation monitoring platform. The sample size was more than 100 vehicles. The distribution of temperature and energy consumption data was shown in Figure 5.

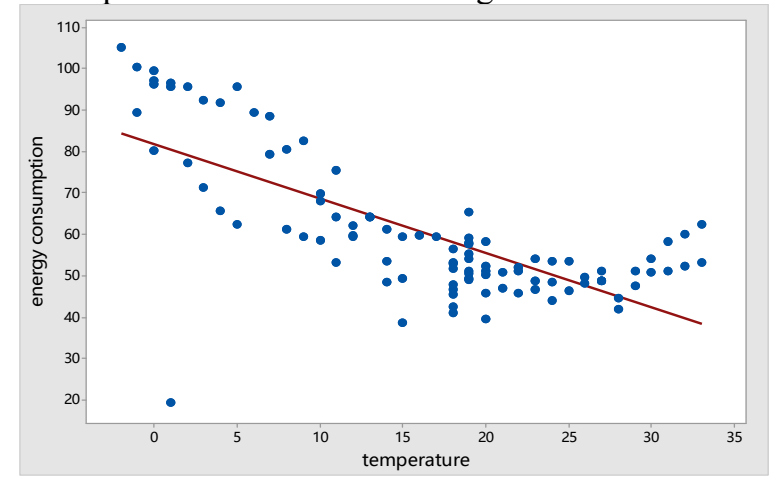

Fig. 5. The distribution of temperature and energy consumption data

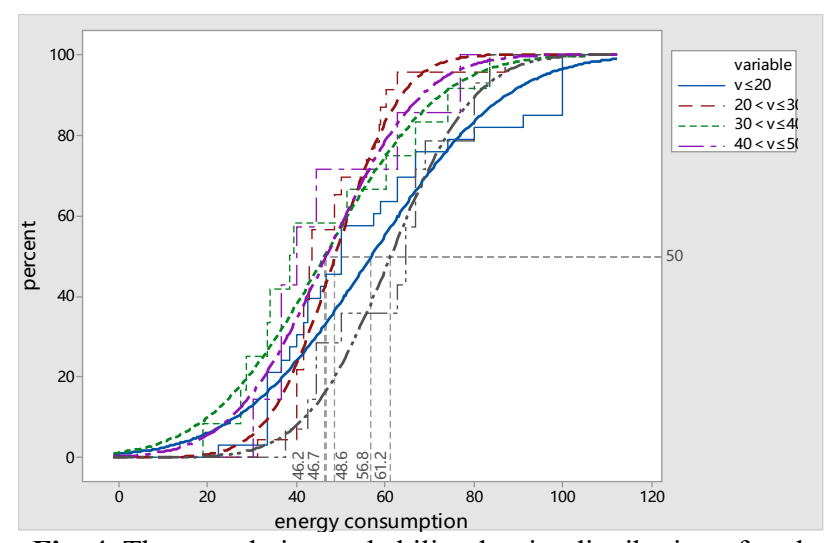

Fig. 4. The cumulative probability density distribution of each speed interval

As can be seen from Figure 5, the operating ambient temperature range of the electric truck is about $0^{\circ} \mathrm{C}$ $\sim 35{ }^{\circ} \mathrm{C}$. The operating energy consumption range is about $40 \mathrm{kWh} / 100 \mathrm{~km} \sim 105 \mathrm{kWh} / 100 \mathrm{~km}$.

In order to ensure that the temperature interval division method is clear when calculating the correction factor, the temperature distribution of electric vehicles was further analyzed. The proportion of each temperature interval was shown in Figure 6.

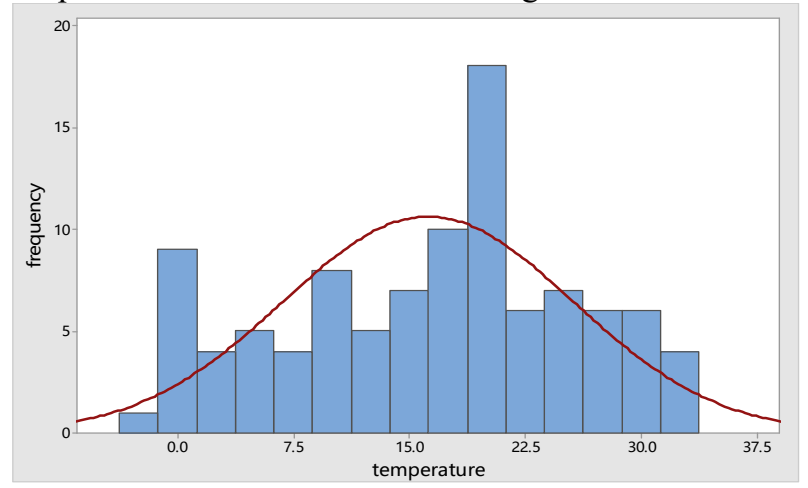

Fig. 6. The proportion of each temperature interval

As can be seen from Figure 6, the maximum average speed of electric trucks is between $17^{\circ} \mathrm{C} \sim 20^{\circ} \mathrm{C}$. More than 50 accounted for a relatively small number. Based on the above analysis, the temperature interval is divided into five, respectively $\mathrm{T} \leq 5^{\circ} \mathrm{C}, 5^{\circ} \mathrm{C}<\mathrm{T} \leq 15^{\circ} \mathrm{C}, 15^{\circ} \mathrm{C}<$ $\mathrm{T} \leq 25^{\circ} \mathrm{C}, \quad 25^{\circ} \mathrm{C}<\mathrm{T} \leq 30^{\circ} \mathrm{C}, \quad \mathrm{T}>30^{\circ} \mathrm{C}$. The interval partition was used to calculate the operating temperature correction for energy consumption.

By using regression analysis and curve fitting in the Minitab software, the cumulative probability density of the energy consumption for electric vehicle models in each temperature range can be calculated. Energy consumption at the $50 \%$ cumulative probability density at the temperature of each interval was successively calculated as shown in the Figure 7.

As can be seen from Fig. 7, the average energy consumption of each temperature interval was calculated. Further, the interval of $25^{\circ} \mathrm{C}<\mathrm{T} \leq 30^{\circ} \mathrm{C}$ with the lowest energy consumption was taken as the benchmark, and the correction coefficient of energy consumption in each temperature interval could be calculated, as shown in Table 2. 


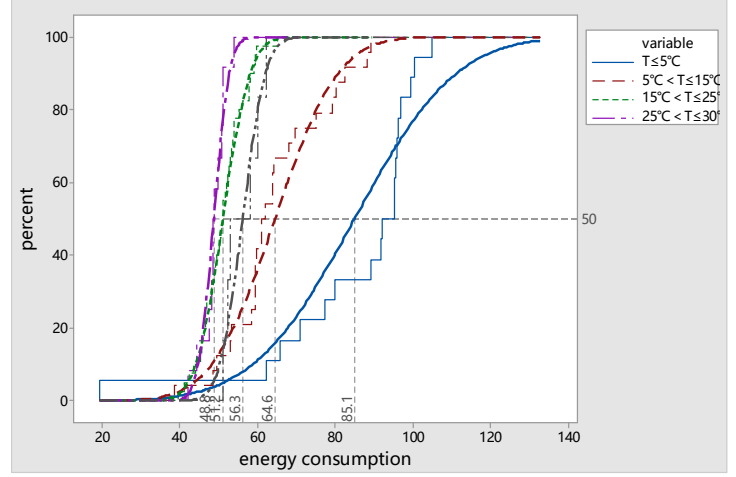

Fig. 7. The cumulative probability density distribution of each temperature interval

Table 2. Table of temperature correction coefficient

\begin{tabular}{|c|c|c|}
\hline $\begin{array}{c}\text { Temperature } \\
\text { range }\end{array}$ & $\begin{array}{c}\text { Energy } \\
\text { consumption }\end{array}$ & $\begin{array}{c}\text { correction } \\
\text { coefficient }\end{array}$ \\
\hline $\mathrm{T} \leq 5^{\circ} \mathrm{C}$ & $85.1 \mathrm{kWh} / 100 \mathrm{~km}$ & 1.74 \\
\hline $5^{\circ} \mathrm{C}<\mathrm{T} \leq 15^{\circ} \mathrm{C}$ & $64.6 \mathrm{kWh} / 100 \mathrm{~km}$ & 1.32 \\
\hline $15^{\circ} \mathrm{C}<\mathrm{T} \leq 25^{\circ} \mathrm{C}$ & $51.2 \mathrm{kWh} / 100 \mathrm{~km}$ & 1.05 \\
\hline $25^{\circ} \mathrm{C}<\mathrm{T} \leq 30^{\circ} \mathrm{C}$ & $48.8 \mathrm{kWh} / 100 \mathrm{~km}$ & 1.00 \\
\hline $\mathrm{T}>30^{\circ} \mathrm{C}$ & $56.3 \mathrm{kWh} / 100 \mathrm{~km}$ & 1.15 \\
\hline
\end{tabular}

\section{Conclusions}

In this paper, the influencing factors of electric vehicles operating energy consumption are deeply analysed. The energy consumption correction coefficient of each influencing factor was calculated and analysed using big data. The research results can provide reference for more accurate estimation of electric vehicles operating energy consumption. The conclusions are as follows:

(1) Theoretical analysis was used to analyse the influencing factors of electric vehicles energy consumption. The results show that the operating speed and the operating environment temperature are the two factors that have the biggest influence on energy consumption after the driver factor is removed.

(2) The cumulative probability density function and curve fitting were used to calculate the speed correction coefficient based on the data collection of actual vehicles energy consumption. The results show that the lowest speed range of vehicles energy consumption is $30<$ $\mathrm{v} \leq 40$. The correction coefficient is different in different speed interval. The highest was 1.32 and the lowest was 1.01 .

(3) The cumulative probability density function and curve fitting were used to calculate the temperature correction coefficient based on the data collection of actual vehicle energy consumption. The results show that the lowest temperature range of vehicle energy consumption is $25^{\circ} \mathrm{C}<\mathrm{T} \leq 30^{\circ} \mathrm{C}$. The correction coefficient is different in different temperature interval. The highest was 1.72 and the lowest was 1.05. Compared with the effect of speed, energy consumption of electric vehicles is more affected by temperature.
Due to the limitations of the research, there are still some areas to be improved in the future research. Since the data collection is only for electric logistics delivery vehicles, the research in this paper fails to cover electric heavy trucks and electric bus with high speed operating conditions, and fails to further study the influence of road slope factors on energy consumption. These will be refined in the further study.

\section{Acknowledgments}

This work was supported in part by the Special funds for basic research operations of Research Institute of Highway Ministry of Transport, grant number (20189050, 2020-9063, 2020-9064).

\section{References}

1. Yuan X M, Zhang C P, Hong G K, et al. Method for evaluating the real-world driving energy consumptions of electric vehicles [J]. Energy, 2017, 141: 1955-1968.

2. Zhou B Y, Xu Y Y, He K X, et al. The on-road testing analysis of travel patterns and the integrated energy consumption of the new energy vehicles in China[C/OL]. 2017 IEEE Vehicle Power and Propulsion Conference (VPPC). Piscataway, USA: IEEE, 2017.

3. Yi Z G, Bauer P H. Effects of environmental factors on electric vehicle energy consumption: a sensitivity analysis[J]. IET Electrical Systems in Transportation, 2017, 7(1): 3-13.

4. LI Jingwei, ZHAO Zhiguo, SHEN Peihong, et al. Research on methods of K-means clustering and recognition for driving style[J]. Automobile Technology, 2018(12): 8-12.

5. Liu K, Wang J B, Yamamoto T, et al. Exploring the interactive effects of ambient temperature and vehicle auxiliary loads on electric vehicle energy consumption[J]. Applied Energy, 2018, 227: 324331. 